\title{
Long Term Neuropsychological Follow-up in Patients With Herpes Simplex Encephalitis and Predominantly Left-sided Lesions
}

\author{
B. LAURENT'1, R. F. ALLEGRI ${ }^{3}$, C. THOMAS-ANTERION', N. FOYATIER', \\ B. NAEGELE-FAURE ${ }^{2}$ and J. PELLAT ${ }^{2}$
}

'Service de Neurologie, Hopital de Bellevue, St-Etienne, France

-Service Dejerine, Hopital de la Tronche, Grenoble, France

${ }^{3}$ Service of Neuropsychological Rehabilitation C.E.M.I.C., Buenos Aires, Argentina

\begin{abstract}
Five patients with predominantly dominant cerebral hemisphere lesions due to herpes simplex encephalitis are described. Verbal amnesia was the main deficit but amnesic aphasia sometimes associated with impairment of remote memory also occurred. Semantic and episodic memory deficits were also explored in one case and the role of the right cerebral hemisphere in facilitating recovery of learning is discussed.
\end{abstract}

\section{Introduction}

Herpetic encephalitis may lead to severe residual neuropsychological deficits, including severe amnesia due to extensive bilateral lesions of the limbic system (Barbizet et al., 1978; Cermak, 1983). When memory impairment is moderate or mild (Klapper et al., 1984) asymmetrical smaller lesions have been demonstrated by MRI and CT scan. Anatomical correlations have been proposed depending on the side of the lesion. Some cases of unilateral lesions of the temporal lobe (i.e. "pseudo" internal temporal lobectomy) have been reported with MRI. We describe five patients with predominant lesions of the dominant hemisphere who have mainly verbal amnesia. Amnesic aphasia was sometimes associated with impairment of remote memory. Internal representation of some words was impaired and made the learning of these difficult. We have also explored episodic and semantic memory in a patient with severe semantic problems and the role of the right hemisphere as a substitution or a help in some learning-tasks.

\section{Patients and Methods}

Five cases of post herpetic encephalitis (involving mainly the left temporal lobe) have been studied with repeated neuropsychological tests. Diagnosis of herpetic encephalitis was based on clinical and radiological observations (Table 1). Language was studied in all cases by BDAE of Goodglass and Kaplan (1976); and learning by the memory scale of Signoret and Whiteley (1979). These memory tests compared learning and recall of verbal and non verbal material ( 12 words or meaningful figures to draw, or a complex figure of 12 items versus a logical story with 12 components). Many other tests have been used to explore the verbal 
TABLE 1 Clinical data

\begin{tabular}{|c|c|c|c|c|c|c|c|}
\hline Cases & Age sex & $\begin{array}{l}\text { Laterality } \\
\text { educat level }\end{array}$ & Clinical onset & $\begin{array}{l}\text { Herpes Ac } \\
\text { serum/CSF }\end{array}$ & $E E G$ & $C T$ scan MRI & $\begin{array}{c}\text { Acyclovir } \\
\text { onset }\end{array}$ \\
\hline 1 & 54 y M & $\mathrm{R}$ group I & $\begin{array}{l}8 \text { days coma } \\
\text { with fever }\end{array}$ & $4(45 d)$ & $\begin{array}{l}\text { Diffuse } \\
\text { slow w. }\end{array}$ & $\begin{array}{l}\text { CT: L temp } \\
\quad \text { lesion }\end{array}$ & 10 th day \\
\hline 2 & 33 y M & $\mathrm{R}$ group I & $\begin{array}{l}\text { Epilepsy, R hemipares } \\
\text { aphasia, fever }\end{array}$ & $5(21 d)$ & $\begin{array}{l}\text { Left temporal } \\
\text { slow w. }\end{array}$ & $\begin{array}{l}\text { MRI: } \mathrm{L} \text { fronto } \\
\text { temp lesion }\end{array}$ & 8th day \\
\hline 3 & 50 y F & R group I & $\begin{array}{l}\text { Headache, confusion, } \\
\text { amnesic aphasia, fever }\end{array}$ & $4(35 d)$ & $\begin{array}{l}\text { Slow periodic } \\
\text { left temp. w }\end{array}$ & $\begin{array}{l}\text { MRI: } L \text { temp } \\
\text { lesion }\end{array}$ & 2nd day \\
\hline 4 & 44 y M & $\mathrm{R}$ group II & $\begin{array}{l}\text { CPS, } R \text { hemiparesis, } \\
\text { aphasia, fever }\end{array}$ & $8(2 d)$ & $\begin{array}{l}\text { Left temporal } \\
\text { status epilept }\end{array}$ & $\begin{array}{l}\text { MRI: L temp } \\
\text { R hippocamp }\end{array}$ & 2nd day \\
\hline 5 & 53 y M & $\mathrm{R}$ group I & $\begin{array}{l}\text { Confusion, epilepsy, } \\
\text { aphasia, fever }\end{array}$ & $8(11 d)$ & $\begin{array}{l}\text { Bitemporal } \\
\text { slow w. }\end{array}$ & $\begin{array}{l}\text { MRI: L temp } \\
\text { R hippocamp }\end{array}$ & 3 rd day \\
\hline
\end{tabular}
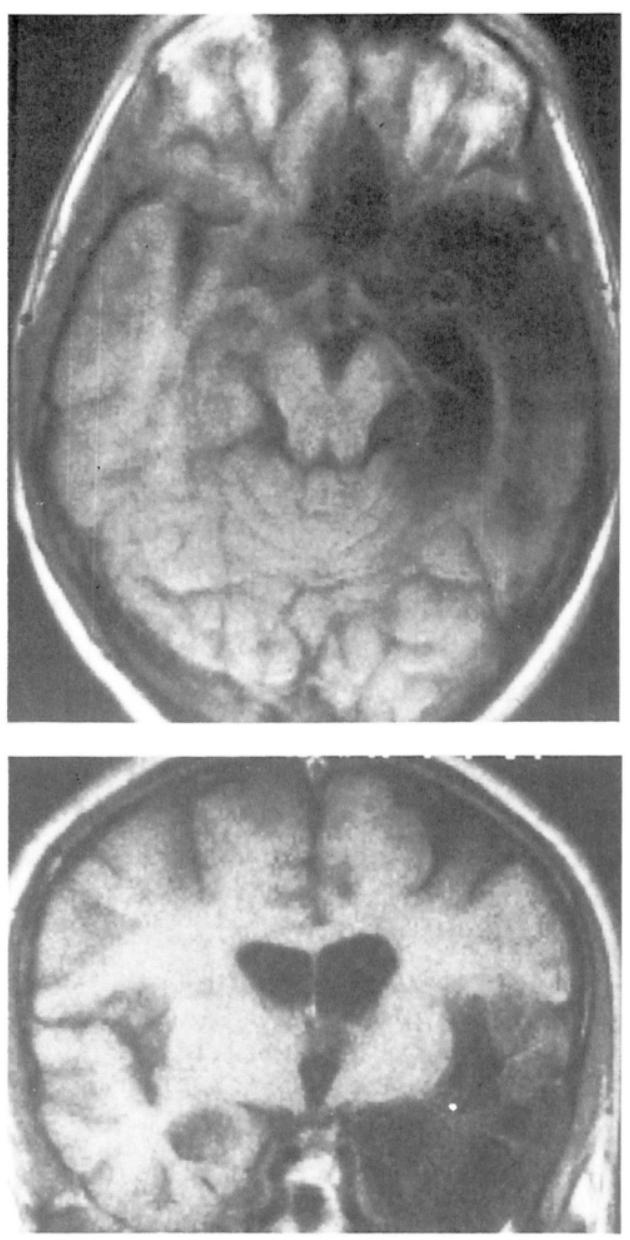

FIG. 1. Case 2: MRI T1 weighted (2 years after onset: horizontal and coronal sections showing hyposignal in all the left temporal lobe with a small hyposignal in the right amygdala and septal area. 


\begin{tabular}{|c|c|c|c|c|c|}
\hline Langage BDAE exam & $\begin{array}{l}\text { Retrograde } \\
\text { memory }\end{array}$ & $\begin{array}{l}\text { Verbal test } \\
144 \text { hatt. }\end{array}$ & $\begin{array}{l}\text { Visual test } \\
144 \text { batt. }\end{array}$ & $\begin{array}{l}\text { Behavioural } \\
\text { disturbances }\end{array}$ & Long term handicap \\
\hline $\begin{array}{l}1 \mathrm{mth}: \text { amnes aphasia } \\
2 \mathrm{mth} \text { : normal }\end{array}$ & Normal & $\begin{array}{l}2,5 \mathrm{~m}: 32 / 72 \\
14 \mathrm{~m}: 39 / 72\end{array}$ & $\begin{array}{l}18 / 72 \\
47 / 72\end{array}$ & No & $\begin{array}{l}\text { Mood behavior change } \\
\text { irritability }\end{array}$ \\
\hline $\begin{array}{l}\text { Onset: global aphasia } \\
5 \text { years: amnes aphasia }\end{array}$ & $\begin{array}{l}\text { Extended deficit } \\
\text { then recovery }\end{array}$ & $\begin{array}{c}2 \mathrm{~m}: 0 / 72 \\
16 \mathrm{~m}: 2,5 / 72\end{array}$ & $\begin{array}{l}16 / 72 \\
43 / 72\end{array}$ & Klüver-Bucy & $\begin{array}{l}\text { Mood change, amnes aph. } \\
\text { no work recovery }\end{array}$ \\
\hline $\begin{array}{l}\text { Onset: amnes aphasia } \\
1 \text { year: normal }\end{array}$ & $\begin{array}{l}\text { Extended deficit } \\
\text { then recovery }\end{array}$ & $\begin{array}{c}1 \mathrm{~m}: 20 / 72 \\
2.5 \text { y: } 39 / 72\end{array}$ & $\begin{array}{l}47 / 72 \\
64 / 72\end{array}$ & No & $\begin{array}{c}\text { Mood change, depression } \\
\text { irritability }\end{array}$ \\
\hline $\begin{array}{l}\text { Onset: amnes aphasia } \\
7 \mathrm{mth} \text { : normal }\end{array}$ & $\begin{array}{l}\text { Extended deficit } \\
\text { then recovery }\end{array}$ & $\begin{array}{l}1 \mathrm{~m}: 42 / 72 \\
7 \mathrm{~m}: 34 / 72\end{array}$ & $\begin{array}{l}64 / 72 \\
68 / 72\end{array}$ & No & $\begin{array}{c}\text { Mood change, irritability } \\
\text { no work recovery }\end{array}$ \\
\hline Lasting amnes aphasia & $\begin{array}{c}\text { Extended semant } \\
\text { retrog amnesia }\end{array}$ & $5 y: 38 / 72$ & $22 / 72$ & No & Amnes aphasia \\
\hline
\end{tabular}

memory for series of words with the help of phonemic, semantic or contextual associations; they will be developed further in two representative cases.

Topography of lesions was determined using CT scan and MRI (slices parallel to a plane through the orbito-meatal line, Fig. 1) which disclosed more accurately the extent of the lesions.

\section{Results of Memory Testing}

\section{Explicit memory}

The results of battery 144 are shown on Figs 2 and 3.

\section{Implicit memory}

Two kinds of test were performed with verbal or picture stimuli. We compared the recall of nine read words and the memory of the form of presentation: three items for each word; spatial location on sheet, ink colour, capital or small hand writing; when the word was forgotten we gave it to the patients who had to say the three patterns; they found much more detail of the presentation than the recalled words (case 3: 4/9 words and 20/27 patterns).

The same kinds of result were obtained with another test where we showed 20 cards with words or pictures of concrete objects, some of which had the two presentations. The patient has to recall the items and the type of presentation (word or picture). The spontaneous recall of items was poor (6/20 for case 3 and $8 / 20$ for case 4 and 5) but the form of presentation was much better recalled (14/20 for case 3 and 5, 18/20 for case 4 ). Thus the patients were able to recall the colour of ink, the place on the paper sheet and the graphism of the "forgotten" words. These observations favour the hypothesis of a normal activity of the right hemisphere still capable of analyzing shape, spatial localization and context of different verbal items. 


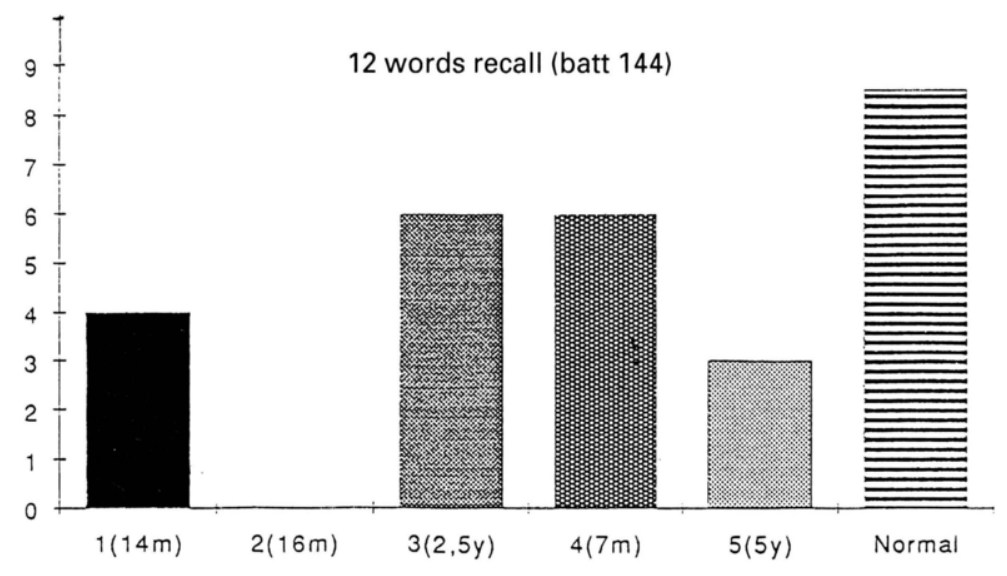

complex figure recall ( batt 144 )

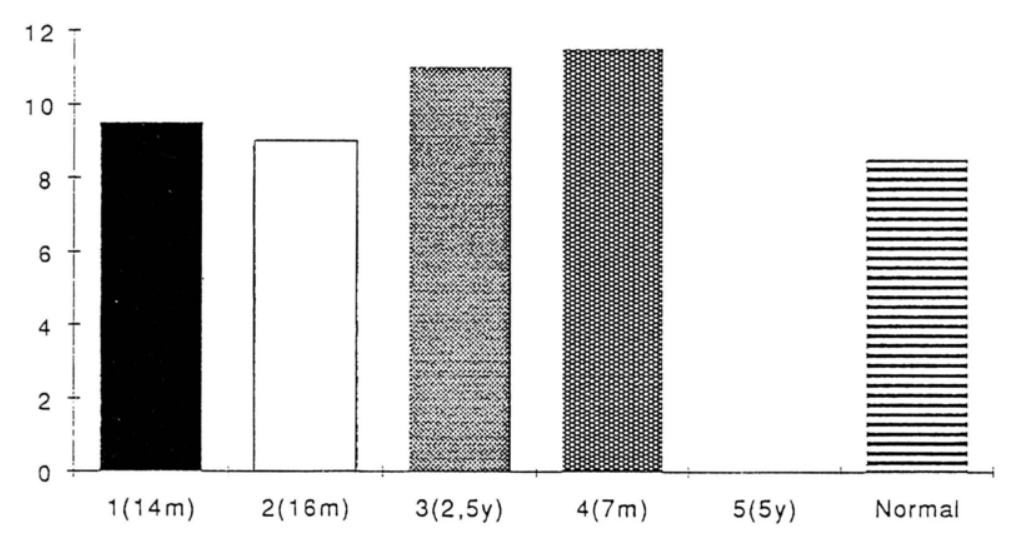

12 simple figures recall ( batt 144 )

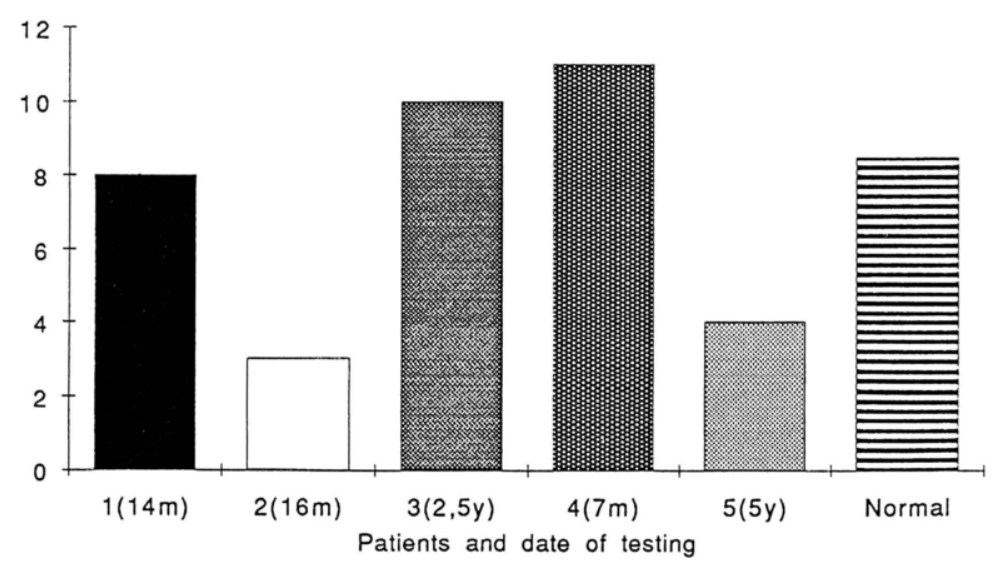

FIG. 2. Verbal and visual episodic memory in the five patients (memory battery 144 of Signoret) in parentheses the date of testing after encephalitis onset in months (m) or years (y). 

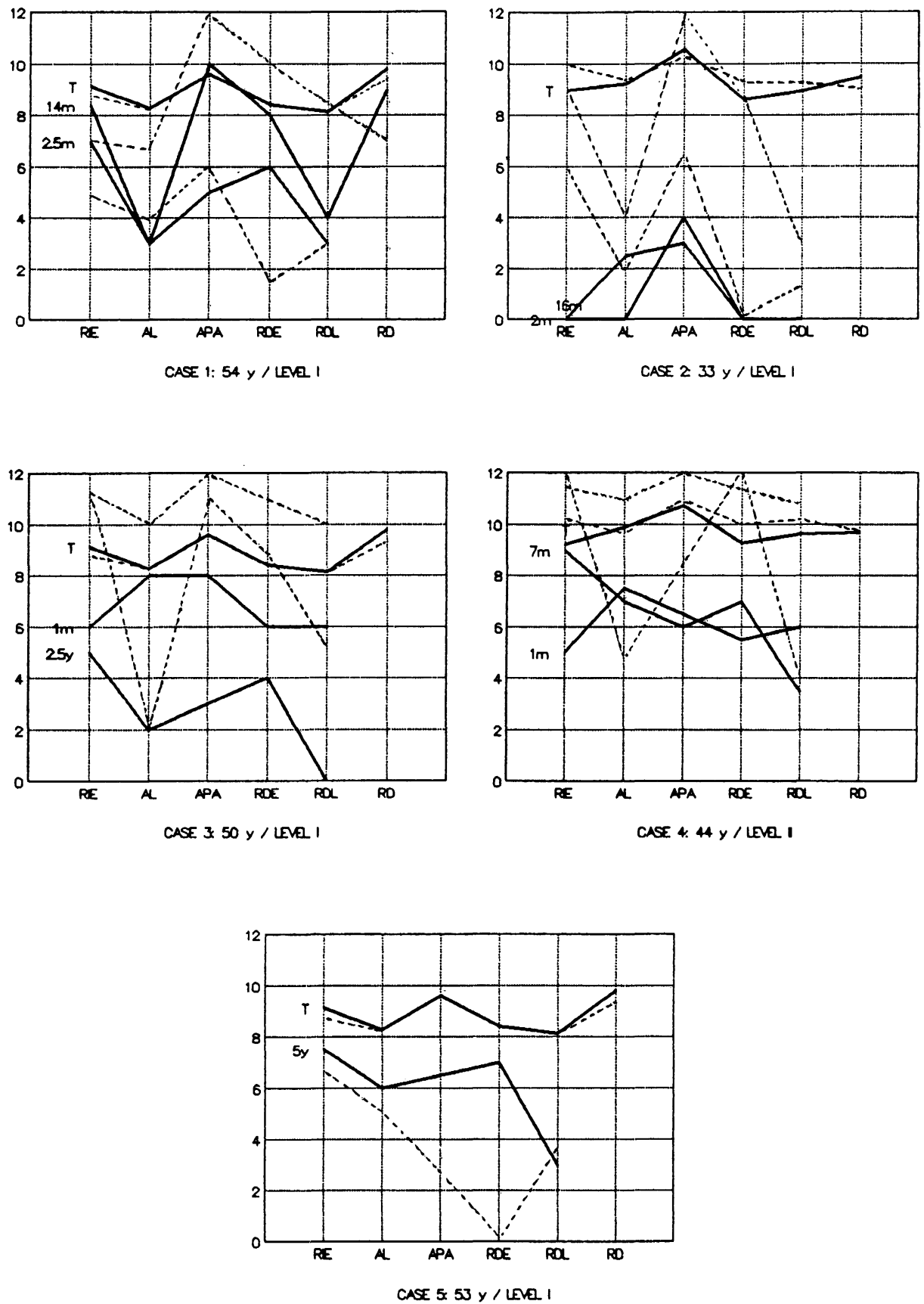

FIG. 3: Results of memory testing with battery 144 (Signoret). T: normal cases matched for age and school level in 3 groups (I: course of studies inferior to 8 years; II: between 8 and 11 years; III: superior to 12 years). Verbal memory; visual memory. RIE, immediate recall of the whole; AL, list learning (series of words or pictures); APA, associative learning of pairs; RDE, long term recall of the whole; RDL, long term recall of the lists; $\mathrm{RD}$, long term recognition. ${ }^{*}$ Curves are associated with the date of testing after onset of encephalitis in days $(\mathrm{J})$, months $(\mathrm{m})$ or years (a) 
Two representative case histories are given below.

\section{Case 4: Mr Gal, 45 years}

Right handed, a lorry driver. Encephalitis consisted of drowsiness then coma with assisted ventilation for 8 days. Neuroradiological investigations showed asymmetrical lesions of the left insula and medial temporal lobes. Acyclovir was given at day 10 and the patient improved progressively. After 4 months, he was discharged and was living at home. He was followed up at the outpatient clinic for 14 months. He remained unemployed and could not do his job of lorry driver since he forgot the orders and the family names. He had poor memory of reading and TV programs. His mood changed and he lost his temper more easily.

Testing was impossible for 2 months because of attention deficit, anterograde amnesia, and amnesic aphasia. For 3 months, the patient confabulated. He had no impairment of remote memory and could perfectly describe what he was doing the day before admission. However, he could not remember the first 2 weeks in the hospital.

\section{Language}

He had an amnesic aphasia and a decrease of verbal fluency for 2 months: eight names beginning with letter " $\mathrm{m}$ " in $1 \mathrm{~min}$, seven names of animals in $1 \mathrm{~min}$. He was able to name few usual objects. He was unable to tell a simple tale. Nevertheless, comprehension, repetition, reading and writing were preserved. His aphasia improved progressively and his tests (BDAE scale of Goodlass and Kaplan, 1972, translated by Mazaux and Orgogozo, 1982 were normal.

\section{Memory}

Battery memory scale 144 (Signoret and Whiteley, 1979) was done 2.5, 5, 14 and 36 months after the onset of encephalitis (Figs 2 and 3).

At 2.5 months. Learning was poor. Confabulations were frequent either spontaneously or induced by tests. Both verbal and visual memory were involved. At 5 months. Verbal memory for series of words was impaired. Some confabulations were produced during the recall of a complex story. Visual memory was normal except for learning series of meaningless simple drawings.

At 14 and 36 months. Verbal memory for series was still abnormal. We compared learning of series and of assocations. We used different semantic technics of facilitation: context or visual clues. We hypothesized that left hemisphere functions are more concerned with logical tasks and that the right hemisphere is most involved in associative tasks (Carbonnel et al., 1986).

Learning of a series of 12 words. Words without any semantic association links and without any facilitation (battery 144): learning 3/12, short term recall 4/12;

words with the same context and forming easy associations (different parts of a railway station): several consecutive learning $7 / 12,10 / 12,8 / 12$ and short term recall $7 / 12$;

words in the same semantic field (cutting objects): several consecutive learning $6 / 12,8 / 12,8 / 12$ and short term recall $7 / 12$; 
words beginning with the same phoneme (e.g. "PA"): consecutive learning $5 / 12,6 / 12,5 / 12$ and short term recall 4/12;

words describing a complex picture shown to the patient (e.g. zoo): several consecutive learning $7 / 12,7 / 12,10 / 12$ and recall $6 / 12$. Naming was wrong for $4 / 6$ items recalled.

Learning of 12 meaningless drawings. Pictures of battery 144 without facilitation: consecutive learning $1 / 12,4 / 12,4 / 12$ and short term recall $6 / 12$. The patient was asked to find a word describing the picture: several consecutive learning $3 / 12,5 / 12,6 / 12$ and short term recall $5 / 12$. Then no verbal facilitation occurred.

Learning of pairs word-picture. Meaningless pictures of battery 144 were used but they were chosen to have a certain associational link with the paired word.

Pair word-picture: the word is given and the patient has to draw the picture: several consecutive learning $3 / 12,4 / 12,5 / 5$ and short term recall $5 / 5$;

Pair picture-word: the picture is given and the patient has to tell the word: several consecutive learning $4 / 12,4 / 12,5 / 5$ and short term recall $0 / 5$.

Summary of memory testing. Verbal series were impaired in all tests for learning and recall.

No facilitation was obtained with a phonetic cue and little facilitation was shown with a semantic cue. Series of words with the same visual categories are learned when the corresponding picture is shown at the same time. Memory of visual series (meaningless pictures to draw) is poor and naming of the picture during the learning task does not help the recall task.

When pairs of word-picture are learned, recall of abstract pictures is excellent when the word is given by the examiner. On the contrary, when the patient has to learn pairs of word-picture he is unable to recall the proper word with the supplied figure and may give some synonym.

\section{Case 5: Mr Duv, 53 years}

A right handed man whose encephalitis included epilepsy, Wernicke's aphasia, behaviour disorders with fever and mild coma requiring assisted ventilation for 15 days. The CT scan showed a large lesion in the left temporal lobe enhanced by contrast. Acyclovir was given at day 3 and the patient improved steadily; 1 month later, he remained aphasic with anomia and semantic disorders, loss of taste and smell, anterograde amnesia with temporal disorientation and extensive retrograde amnesia for episodic events and most semantic knowledge.

The patient presented 5 years after encephalitis because of severe persistent amnesia even for general everyday knowledge (cooking, gardening, meaning of current words).

His wife has observed a relatively selective deficit for natural objects (animal, fruits, trees, etc.) as opposed to hand-made ones. In spite of good skills in gardening before his illness, he was unable to distinguish the leaves of the trees or vegetables, to find the words for fruits and plants or to evoke the correct image on hearing the word. Moreover he could not function properly with these forgotten 
TABLE 2. Naming and knowledge of natural vs. man-made objects (case 5)

\begin{tabular}{|c|c|c|c|c|c|c|c|c|}
\hline & $\begin{array}{c}\text { Vegetables } \\
\text { and fruits }\end{array}$ & Animals & Cars & Tools & Clothes & Personalities & Business & Colors \\
\hline $\begin{array}{l}\text { Evocation } \\
\text { (Thurstone) }\end{array}$ & 13 & 17 & 12 & 14 & 15 & 0 & & \\
\hline $\begin{array}{l}\text { Word-evocation } \\
\text { on definition }\end{array}$ & $4 / 10$ & $2 / 10$ & & $6 / 10$ & & & $2 / 10$ & \\
\hline Visual naming & $7 / 16$ & $5 / 16$ & $9 / 15$ & $9 / 15$ & $9 / 15$ & $0 / 10$ & & $1 / 10$ \\
\hline $\begin{array}{l}\text { Semantic } \\
\text { knowledge }\end{array}$ & $5 / 16$ & $3 / 16$ & & $11 / 15$ & $12 / 15$ & & & \\
\hline
\end{tabular}

semantic fields and he had planted haricot beans too close, gathered the strawberries too early. In contrast, he could manipulate tools, car or other hand made objects, correctly.

The testing was carried out 5 years after the onset when anterograde and amnesic aphasia had improved greatly.

\section{Language (BDAE scale of Goodglass and Kaplan)}

Spontaneous expression was fluent without paraphasia; repetition was normal with a span of 7 for digits and trisyllabic common words; the deficit of naming appeared for some categories where he could more easily find the generic name (insects, vegetables) than the specific one; when he had to define a word, in $1 / 3$ of the cases he described the context or category but could not give information about the form, colour or function. Abstract and rare words as proverbs were less defined. Syntactic structure of phrases was correct.

Comprehension was normal on arrangement of complex figures of actions (Montreal aphasia scale) and for complex or sequential orders (TOKEN test). He could criticize absurd stories but his answers were long and slow with many digressions.

Writing disclosed many orthographic mistakes whatever the word categories.

$$
\text { Tests }
$$

Many tests have been performed to understand his particular form of semantic amnesia (Table 2).

Verbal fluency $(1 \mathrm{~min})$. 15 clothes, 12 carriage resources, 13 vegetables, 18 professions, 14 tools and 17 animals; a name of a French politician and two actors.

Words comprehension. He could not define precisely many "natural" words (animals, vegetables) correctly used in fluency test, as he did for clothes, tools or professions. The category knowledge was preserved: when he has to find the category of three words which are read or heard, or to complete the series he succeeds for 10 lists (insects, countries, music instruments, professions, etc.). To find a word from its definition, he succeeded with $6 / 10$ tools, $4 / 10$ fruits, 2/10 animals. 
Naming and general knowledge. Colors: some errors in naming but correct designation and matching;

tools: naming 12/16; knowledge (gesture, purpose, etc.) 15/16;

fruits and vegetables: naming $7 / 16$; knowledge $5 / 16$, with variability of responses between two tests;

animals: naming 5/16; knowledge 3/16.

We have mixed 30 pictures of common man-made objects with natural ones. Nine/15 man-made objects were named and 11/15 correctly defined or used, for $3 / 15$ and $4 / 15$ for natural current ones.

Classification of pictures (animals and fruits). When he had to classify the pictures of animals with pictures showing the country, type of living (air, water, ground, domestic, etc.), foods, skins (hair, scale, feather), he obtained 30/35 correct responses; the same type of test with the fruits showed 20/40 correct responses; the results were nearly the same if the classification involved written stimuli so the semantic deficit did not depend on verbal presentation.

Lhermitte's test for the semantic fields of concrete and abstract words. For all the words especially the abstract ones it showed smaller fields without hierarchy. The patient can understand and to some extent define words with some semantic associations (more often contextual than abstract ones). However he cannot find the hierarchy of the found words.

\section{Verbal episodic memory}

In spite of a WAIS IQ 95 (verbal 89, practical 105), a clear deficit appeared in all tests of verbal memory (logical, serial or associative): $3 / 12$ recalled words, 14/24 items of a logical story (battery 144; Figs 2 and 3).

Learning of series of 30 words in three trials. Without any links and any facilitation: recall 5/30;

with phonemic links (beginning by PA) $3 / 30$;

30 words with several links: 10 with semantic links (cutting objects), 10 belonging to the same context (railway station) and 10 intruders: recall 8/30 with six "contextual" words and two "semantic."

\section{Discussion}

All five patients had serial neuropsychological evaluations. Progressive improvement (mainly of amnesic aphasia) was observed within the first months. Neuropsychological signs were similar to those previously described in association with unilateral temporal lobectomy (Penfield and Milner, 1958). The prognosis in all five patients was good and they were able to live at home with their families. However, three patients could not do their jobs. Such a benign evolution had been previously described (Radermecker et al., 1962). Buge et al. (1988) have reported a good prognosis in eight out of 12 patients with herpetic encephalitis with a follow-up of 3 to 5 years. Most authors have insisted on the benefit of early antiviral treatment, as occurred in our series. However, correlations with size and localization of the lesions (i.e. unilateral or bilateral) were not done (Davis et al., 1983, Kapper et al., 1984). 
In our patients repetitive CT scan and MRI have shown predominant asymmetrical left sided lesions. Medial temporal, medial frontal and insular areas were involved. There were no anatomical lesions in the right hemisphere with CT scan, but MRI showed in almost all the cases (cases 2, 4 and 5) mild lesions of the right medial temporal areas. MRI is a useful tool for an early diagnosis of post herpetic encephalitis and to determine the extent of lasting lesions. Moreover lesional asymmetry is well observed with MRI (Schroth et al., 1987). Asymmetry of lesions was reported in $78 \%$ out of 55 patients (Neils et al., 1987) and in 12 out of 19 patients (Buge et al., 1988).

The neuropsychological deficits are well correlated with the left temporal location of encephalitis as in temporal lobectomy previously reported.

\section{Amnesic aphasia and semantic amnesia}

Amnesic aphasia with semantic deficit is characterized by an impairment in the retrieval of words (they are missing from the semantic stock): facilitation does not help the patient, and the word seems odd or unknown. Lasting amnesic aphasia is well demonstrated in case 5, whereas in all the other cases the trouble disappeared in a few weeks. Tests were performed in order to explore, naming, classification and designation of concrete or abstract words as well as pictures associated with the "forgotten" word. Lack of words was more evident during the naming test and was not modified when the stimulus was tactile, auditory or visual. In most of the tests the internal image of the word was explored (i.e. definition and word usage) as well as the ability to recall a word.

A good test to explore the deficit in semantic processing in spite of naming deficit, is to match the pictures of objects with words, with their written definitions, or with other pictures concerning some characteristics of objects. $\mathrm{He}$ mainly failed when he was asked to form associations between pictures and abstract words or when he had to classify categories of objects. Some of the results are disappointing by dissociation and variability within the different tests; for example, he could associate the picture and the name of a butterfly but he defined it as a bee. He could associate the picture and the definition of a gooseberry but he called it as a raspberry. Sometimes the picture-naming association seems to be preserved but the patient does not know what the meaning is. We studied the naming in this patient using four categories: tools, jobs, fruits and animals since we had been told by his wife that he had problems with many everyday objects. Span was similar in the four categories but when naming was explored, the patient's ability was better for tools or jobs either spontaneously or induced by facilitation. In contrast to the span, the number of words obtained during the naming task of fruits, vegetables or animals was much smaller. A successful performance in naming was sometimes associated with a poor knowledge of the meaning of the word, and the performance should not be considered as the good standard in exploration of semantic fields. This dissociation between naming, span, and knowledge in the same semantic field seems to be paradoxical: it raises the question of the nature of the naming deficit either as anomia (verbal, auditory or tactile), or deficit in the verbal and visual categorization of a same stimulus. 
The naming and general meaning of man-made objects was performed better than natural objects (if words of equal frequency are used). In order to explain this difference, we hypothesize that man-made objects have a specific usage and that they can more easily be associated with a group of visual or tactile cues. Naming of jobs can be made easier when it is associated with a very specific task or tool.

For natural objects these gimmicks cannot be used. Similar findings have already been reported (Warrington and MacCarthy, 1983). The authors studied an aphasic patient with a huge dissociation: she understood words concerning animals, flowers and food better than words concerning objects. Warrington and Shallice (1984) described four patients who understood words concerning actual objects but were unable to understand those associated with animals or trees.

When verbal exploration of one semantic field is abnormal, the use of actual objects belonging to this field was abnormal also (procedural memory). The patient forgot how to grow vegetables or how to wear some clothes (e.g. he was wondering whether he should wear his pullover under his shirt but he was able to put it on properly). This has already been described by De Renzi et al. (1987): his patient was unable to name the vegetables he was using to cook a soup and he had forgotten how to cook the soup. It has also been described in a patient with bilateral post-herpetic encephalitis (Bakchine et al., 1986).

\section{Impairment of Verbal Episodic Memory}

Memory in our patients was mildly impaired probably due to asymmetry and the relatively small size of the lesions. However, at the early stage, diffuse amnesia was observed as occurs in diffuse encephalitis. This early anterograde and retrograde amnesia can be very severe but it usually improves steadily. Only the first days or weeks of hospitalization are permanently forgotten. Confabulations are frequent either sponteanously or induced by the tests. They are mainly observed when the septal or orbito-frontal areas are damaged (Damasio et al., 1985). They are often associated with impairment of remote personal and episodic memory and chronology of the different events is usually impaired.

Impairment of retrograde memory is variable from one patient to another and does not parallel the intensity of anterograde amnesia. In four of our patients retrograde memory was severely impaired at the begining of the disease and even involved the earliest events of personal history. It improved in a few weeks. In one patient it persisted as previously reported in the literature (Cermak and O'Connor, 1983).

Usually patients have a severe anterograde amnesia: they complain of forgetting names, films, books and orders. The neuropsychological deficit involves only memory functions, and IQ logical tests or tests concerning strategy are usually normal. The anterograde memory deficit concerns mainly verbal material (e.g. words series). No facilitation is obtained using associational or logical links. Logical analysis of verbal material is possible, but this strategy is not memorized by the patient. Moreover if the same strategy is given during the recall task, it does not improve the results (Cermak and O'Connor, 1983). Visual memory is much better but not entirely normal. This may be due to small lesions in the right hemisphere (cases 1, 2, 4 and 5). The alternative hypothesis is that verbalization may 
be helpful even in these visual tests. A clear-cut distinction of hemispheric functions cannot be completely done with tests concerning the learning of words and meaningless figures. The right hemisphere can play a supporting role in strategies of verbal memory. As a parallel, visual memory can be improved by verbal and logical strategies.

We explored in our five patients the different facilitations in the learning of verbal series: phonemic, semantic, logical, and context associations. We considered that the right hemisphere could play a useful role in some tasks: global analysis of collections of data, and memory of context related items (Carbonnel et al., 1986).

During learning tasks of series of words phonologic and semantic cues are useless. The most recent words in the list are better memorized (recency phenomena); it seems to be the reflection of lack of semantic strategy due to lesions of the left hemisphere. However, this phenomenon is not observed if the patient is asked to learn a series of words that belong to the same visual context. When the learning of words concerns those describing a complex picture or belonging to the same visual context (different parts of a station) the recall was much better. The results emphasize the role of the right hemisphere in learning lists of words where visualization or contextual grouping are possible whereas the left hemisphere is necessary for phonologic or semantic processing.

\section{Right Hemisphere Integrity}

This integrity, even incomplete, can explain the good results in visual memory on battery 144. It explains the type of cueing in the learning of words as explained above. This kind of processing with contextual and concrete cues appears as well in visual learning: we tested the learning of pictures which could be matched either semantically or contextually. The patients matched easily all the pictures but recalled much better the contextually bound ones. We found the same results with lists of words connected semantically or concretely: the patients detected easily the tie but forgot the logically associated words. The preservation of implicit memory favour also the hypothesis of a normal activity of the right hemisphere still capable of analyzing shape, spatial localization and context of different verbal items.

All these data give information on the right hemisphere processing including for the verbal learning. The classical dichotomy left hemisphere-verbal memory with regard to right one visual memory must be surpassed with a more cognitive approach.

\section{Behavioural Sequelae}

Disorders of behaviour or mood are usual even if they are less pronounced than in the classical Klüver-Bucy syndrome of the extensive bilateral forms. In the second patient with an associated small lesion in the right amygdala and septal area (figure) disorders of behaviour were permanent and severe: improper act or 
words, indecency, hyperphagia and rage attacks. During one of these he bit the ear of his wife because she delayed her response to one question. For the other cases the changes were confined to mood with placidity, emotional indifference, apathy, irritability and depressive tendency. Buge et al. (1988) described the same behavioural disorders in half of their patients with favourable evolutions and mild sequelae.

\section{Conclusion}

The neuropsychological tests are well correlated with left lateralization of encephalitis. The sequels are mild in comparison to usual bilateral forms. In all cases the amnesic aphasia is a dominant feature of onset but progressively disappears in a few months. In one case, with an associated right temporal lesion, the amnesic aphasia remained significant 5 years after onset with a sematic amnesia for the knowledge of words, pictures, concepts, colours. The deficit affected preferentially the natural objects with loss of the corresponding words, mental pictures, and use.

The retrograde and anterograde visual memory are nearly preserved. The amnesia concerns the verbal information especially the logical and abstract, with a better learning of concrete words belonging to the same visual context. The semantic or phonemic cues are usefulness to learn verbal series. The incident memory of the presentation of words is preserved in spite of forgetfulness. All these dissociations are relevant to understand the role of substitution of the right hemisphere in the memory when the left temporal lobe is destroyed.

\section{References}

Bakchine, S., Chain F. and Lhermitte F. (1986). Syndrome de Klüver-Bucy humain complet après une encéphalite à herpès simplex type 2. Rev'ue Neurologique, 142, 126-132.

Barbizet, S., Duizabo P. and Porier J. (1978). Etude anatomoclinique d'un cas d'encéphalite amnésiante d'origine herpétique. Revue Neurologique, 134, 241-253.

Buge A., Chamouard J.M. and Rancurel G. (1988). Le pronostic des encéphalites herpétiques. Etude rétrospective de 19 cas. Presse Médicale, 17, 13-16.

Carbonnel S., Rivet M.D. and Pellat J. (1986). Hemispheric asymmetric in semantic processing. Presented at the 3rd European Workshop on Cognitive Neuropsychology, Bressanone, Italie.

Cermak L.S. and O'Connor M. (1983). The anterograde and retrograde retrieval ability of a patient with amnesia due to encephalitis. Neuropsychologia, 21, 213-234.

Damasio A. and Vanhoesen G. (1985). The limbic system and the localisation of herpes simplex encephalitis. Journal of Neurology, Neurosurgery and Psychiatry, 48, 237-301.

Davis L. and McLaren L. (1983). Relapsing herpes simplex encephalitis following antiviral therapy. Annals of Neurology, 13, 192-195.

De Renzi, E., Liotti, M. and Nichelli, P. (1987). Semantic amnesia with preservation of autobiographic memory. A case report. Cortex, 23, 575-597.

Ducarne, D.E. and Ribeaucourt, B. (1976). “Test pour l'Examen de l'Aphasie." Centre Psychologie appliquée, Paris.

Goodglass, H. and Kaplan, E. (1972). “The Assessment of Aphasia and Related Disorders.” Lea and Fibiger, Philadelphia. 
Klapper, P.E., Cleator, G. and Longson, M. (1984). Mild form of herpes encephalitis. Journal of Neurology, Neurosurgery and Psychiatry, 47, 1247-1250.

Lhermitte, J. (1971). Contribution à l'étude des troubles sémantiques dans l'aphasie. Revue Neurologique, 125, 81-101.

Mazaux, J.M. and Orgogozo, J.M. (1982). “Echelle d'Evaluation de l'Aphasie.” Scientifiques et Psychologiques.

Neil, S., Lukin, R., Tomsick, T. and Tew, J. (1987). Magnetic resonance imaging and computerized tomography scanning of herpes simplex encephalitis. Journal of Neurosurgery, 67, 592-594.

Penfield, W. and Milner, N. (1959). Memory deficit produced by bilateral lesions in the hippocampal zone. Archives of Neurology and Psychiatry, 79, 475-497.

Radermecker, J., Flament, G., Guazzi, G. and Troch, G. (1962). Encephalite aigue nécrosante avec survie sans séquelle neuropsychiatrique. Revue Neurologique, 4, 106, 368-380.

Schroth, G., Gawehn, J., Thron, A., Vallbracht, A. and Voigt, K. (1987). Early diagnosis of herpes simplex encephalitis by M.R.I. Neurology, 37, 179-183.

Signoret, J.L. and Whiteley, A. (1979). Memory battery scale. International Neuropsychological Society Bulletin, 2, 26.

Warrington, E.K. and McCarthy, R. (1983). Category specific access dysphasia. Brain, 106, $859-878$.

Warrington, E.K. and Shallice, T. (1984). Category specific semantic impairments. Brain, 107, 829-853. 


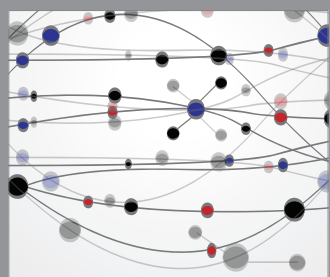

The Scientific World Journal
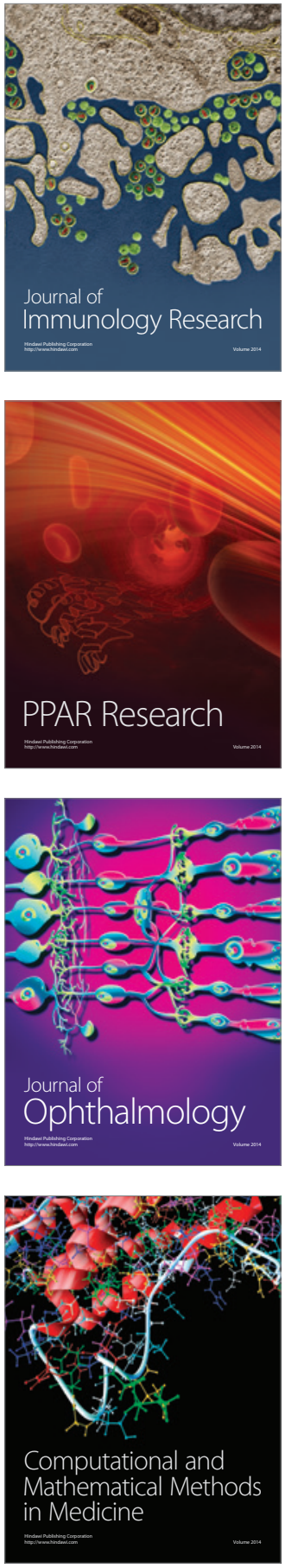

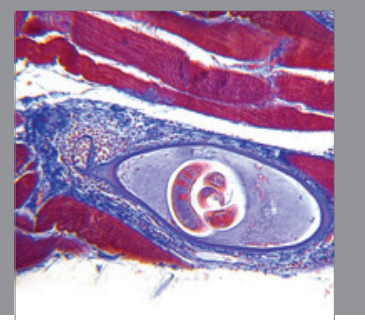

Gastroenterology

Research and Practice
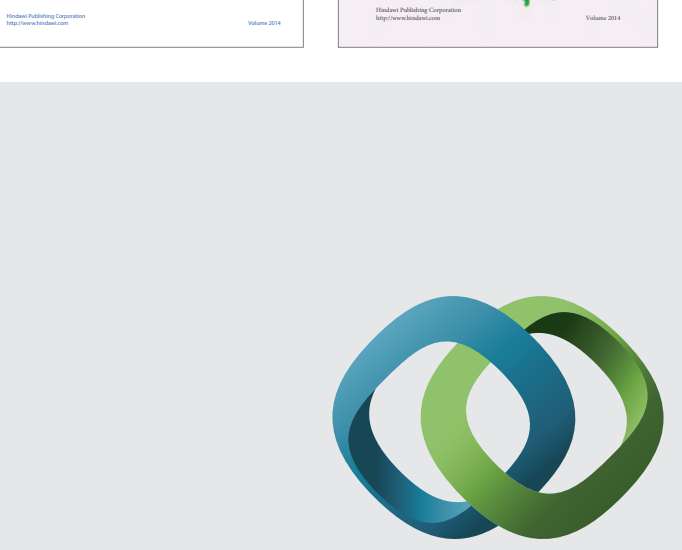

\section{Hindawi}

Submit your manuscripts at

http://www.hindawi.com
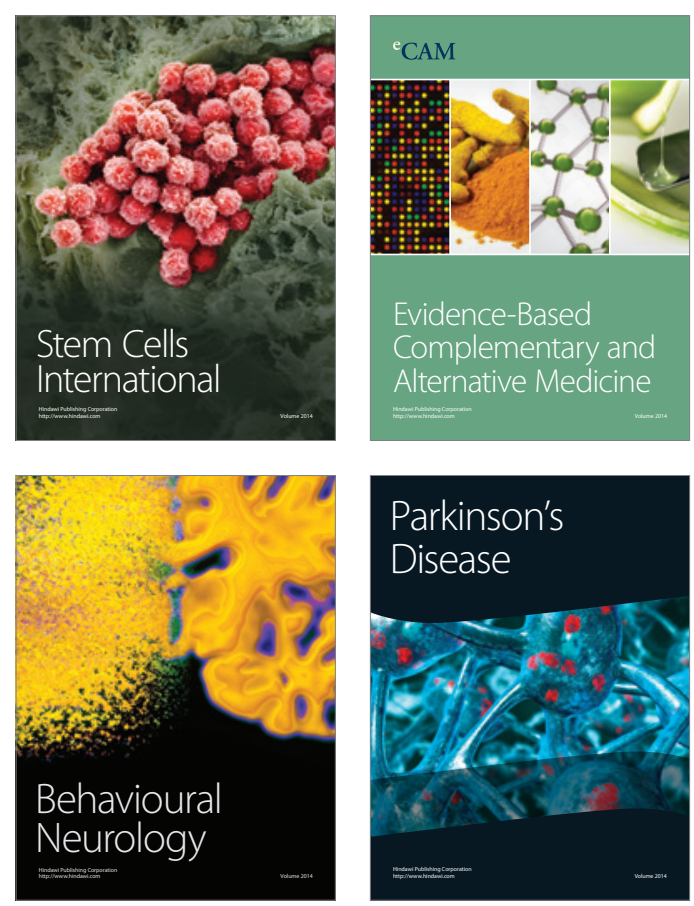

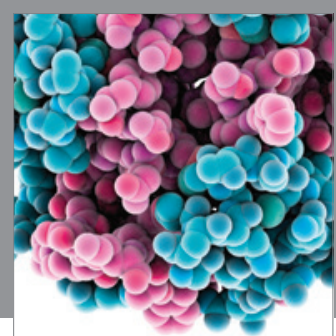

Journal of
Diabetes Research

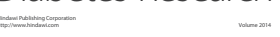

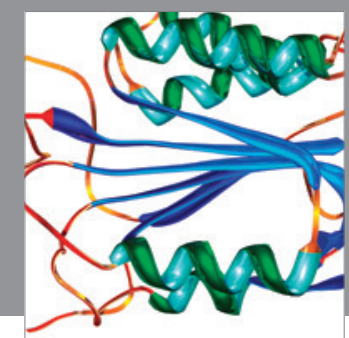

Disease Markers
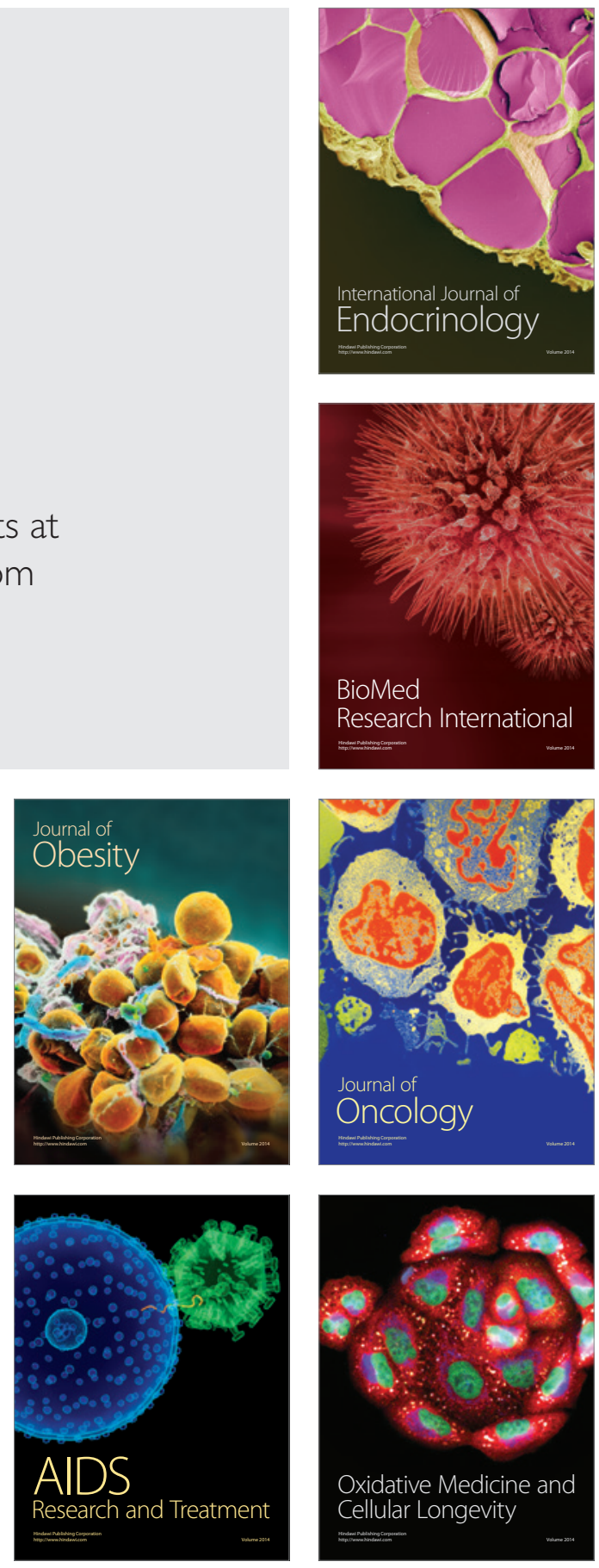